\title{
Geospatial clustering of newly diagnosed HIV- infected adults in Cross River State helps define new "hotspots"
}

Michael Egbe ${ }^{1}$, Antor O. Ndep ${ }^{2 *}$, Philip Imohi ${ }^{1}$ Kingsley Obase ${ }^{1}$, Frank Eyam ${ }^{1}$, Cajetan Obi ${ }^{1}$, Peter Agada1, Nnennaya Igwe1, Augustine Idemudia1, Ikechukwukah Abah¹, Betta Edu

'Department of HIVIAIDS Research, Enareh Public Health Consultancy, Calabar, Cross River State, Nigeria, ${ }^{2}$ Department of Public Health, Faculty of Allied Medical Sciences, University of Calabar, Nigeria, ${ }^{3}$ Office of the Commissioner, Cross River State Ministry of Health, Calabar, Nigeria.

\begin{abstract}
Introduction: A hotspot is a geographical location having evidence of high STIs/HIV prevalence, and/ or behaviors that put people at high risk of becoming infected. Therefore, Nigeria, with almost two million people living with HIV, could be considered a giant "hotspot." The main aim was to describe how the geospatial clustering of newly diagnosed HIV-infected adults in Cross River State helps define new "hotspots."

Methods: Secondary data collected between January 2020 and March 2020, identified and mapped around a presumed hotspot's radius of influence (ROI), were analyzed using a "Hotspot Analysis" plugin in QGIS software. With a sample size of 3019, both seropositive and seronegative results were geo-referenced and the resultant map was analyzed to determine HIV-positive clusters.
\end{abstract}

Results: From the 3019 spatial locations mapped, 720 (23.9\%) were positive cases. Of these, 328 (45.6\%) were thus estimated as being associated with the presumed hotspots. The remaining 392 (54.4\%) were positive cases identified outside of the ROI of the originally presumed hotspots. The total number of mapped HIV testing services (HTS) points (both negative and positive cases) within the hotspot ROI was 1319, while those outside of the hotspot ROI were 1700.

Conclusion: Unique hotspots where social gatherings occur tended to have a wider ROI. Targeted testing in these hard-to-reach communities is recommended.

Keywords: Hotspots; HIVIAIDS; geographic information system; geospatial; clustering; transactional sex; maritime work

*Corresponding author: Dr. Antor O. Ndep, Department of Public
Health, Faculty of Allied Medical Sciences, University of Calabar,
Nigeria. Phone: +234-9060381917. E-mail: drndep@gmail.com

Submitted: 09 April 2020/Accepted: 05 June 2020

DOI: https://doi.org/10.17532/jhsci.2020.912

UNIVERSITY OF SARAJEVO FACULTY OF HEALTH STUDIES

\section{INTRODUCTION}

The World Health Organization (1) defined a hotspot as a geographical location that has evidence of the high prevalence of HIV, STIs, or behaviors that put people at high risk of becoming infected 
with HIV. Therefore, a hotspot could represent an area with a high prospect of finding people at risk of infection or already infected with HIV.

WHO (2013) indicated that knowing your epidemic requires you to know your geography and the behaviors that put people at increased risk of infection. Cross River State has a sizeable population that lives in poor rural areas depending on subsistence farming. Furthermore, border towns are locations of increased socioeconomic activities with a possibility of transboundary movement of people infected with the virus. Cross River State is bounded in the east by the Republic of Cameroon which has a high prevalence of HIV. Border communities in Akamkpa, Akpabuyo, and Bakassi local government areas (LGAs) share similar characteristics of being poor, rural, and dependent on maritime activities for trade and livelihood, making them potential hotspots for HIV infection/ transmission.

Patent medicine vendors (PMVs) receive the most patronage from members of rural communities because they are the closest and easiest points of access to medical care in most developing countries (2). PMVs constitute good spots where undiagnosed HIV carriers are likely to access medical services, particularly individuals who are in the early phase of the infection. Other potential hotspots in both rural and urban communities are medical laboratories.

Nigeria is one of the most religious nations in the world, being the $5^{\text {th }}$ and $6^{\text {th }}$ largest Muslim and Christian populations, respectively, $48.1 \%$ of this most populous African nation are Christians, while Muslims make up 50\% of the population (3). Considering the religious fanaticism of the large majority of individuals who believe in, and patronize healing homes and prayer houses $(\mathrm{PH})$, such places are classified as hotspots for HIV case identification.

Hospitals and health posts play different roles in providing healthcare services to different categories of patients, therefore, are considered hotspots for HIV case identification. Traditional birth attendants (TBAs) serve as a point of care for pregnant and expectant mothers. The historical significance of this form of healthcare for pregnant women, coupled with the traditional and cultural belief that birth attendants provide better care (physical and spiritual) to pregnant women, has made TBAs an essential part of the healthcare system in Nigeria $(4,5)$. Since almost $25 \%$ of children born with HIV worldwide are born in Nigeria, targeted testing for pregnant women is one of the strategies for HIV case identification, introduction to care, and prevention of maternal to child transmission of HIV (PMTCT).

Brothels and clubhouses are areas with an increased risk of HIV transmission. In Nigeria, commercial sex workers are classified into brothel and non-brothel based. While non-brothel-based sex workers are more dispersed, brothel-based sex workers and those who operate in clubhouses can be tracked and provided with targeted HIV services. In its 2018 report entitled "Miles to Go," The Joint United Nations Programme on AIDS noted that sex workers are 13 times more likely to become infected with HIV than adults in the general population $(6,7)$. While these conditions also put their partners on the increased risk of infection, such as brothels and clubhouses are potential structures for increased HIV positivity, making them HIV hotspot for geographic information system (GIS) mapping. The main aim of this study was to describe how the geospatial clustering of newly diagnosed HIV-infected adults in Cross River State helps define new "hotspots."

\section{METHODOLOGY}

Using a cross-sectional study design, GIS techniques were deployed to map the spatial locations of 3019 persons tested for HIV in the community between January 2020 and March 2020 as part of community art management (CAM) activities in 13 LGAs of Cross River State, Nigeria. Originally targeted "hotspots" such as PMV, healing homes, TBA, community pharmacies, $\mathrm{PH}$, and Fishermen Jetties were also mapped as locations with high potential to yield HIV positive cases as a means of efficiently guiding CAM team efforts. All persons tested within a 75-m radius distance from the mapped location of the pre-targeted hotspot; referred to as the "Radius of Influence" (ROI) were assumed to be associated or gotten from that hotspot as there were no specific attributes in the 
source data defining these categories (i.e., persons tested within and outside of the pre-targeted hotspots). Conversely, all persons tested for HIV outside the ROI were assumed not to be associated with the pre-targeted hotspots.

The HIV testing services (HTS) dataset (comprising all positive and negative cases) identified outside the pre-targeted hotspots (1700 in total) were analyzed to infer or deduce new locations of hotspots. The "Hotspot Analysis" plugin in QGIS - a free and open-source desktop GIS software - was used to implement spatial autocorrelation analysis (8) using the Local Getis-Ord Gi* statistics algorithm (9) which is a type of exploratory spatial data analysis technique that aims to detect significant local pockets of clusters in a spatial dataset (10). When applied, the GI* (pronounced G-i-star) local statistics sought to detect aberrant locations (hotspots or coldspots) in the spatial distribution of a given variable. The GI* statistics algorithm practically compares local averages with the global average to identify the presence of significant-high values (or low values) clusters (9). Local averages were computed by considering, for any location (or feature in a dataset), a set of neighbor elements within a specific distance from the focal position. For this reason, the plugin requires to specify a "Distance Band" using the same unit of measure of the projected coordinate system of the input shapefile (10).

According to Oxoli, Daniele (2018) "The Hotspot analysis plugin computes $Z$-scores and $p$-values (under the complete spatial randomness hypothesis) of the $\mathrm{Gi}^{*}$ local statistic (Getis and Ord, 1992; Getis and Ord, 1996), Anselin Local Moran's I (Anselin, 1995), and Local Moran Bivariate (Wartenberg, 1985; Anselin et al., 2002) for each geometry of a shapefile, with an assigned projected coordinate system and (at least) an associated numerical attribute." The numerical attribute used for this study was the "HIV status." Persons who tested positive were coded as 1 and those who tested negative were coded as 0 . The input HTS data were stored in ESRI shapefile format and projected to the Universal Transverse Mercator (UTM) coordinate system (WGS 84/UTM zone 32N) which covers the study area.
The QGIS hotspot analysis plugin computes z-scores and $p$-values (under complete spatial randomness hypothesis) of the $\mathrm{Gi}^{*}$ local statistic $(9,11)$. Anselin Local Moran's I (12) and Local Moran Bivariate $(13,14)$ for each geometry of a shapefile with an assigned projected coordinate system and (at least) an associated numerical attribute (15). The numerical attribute used for this study was the "HIV status." Persons who tested positive were coded as 1 and those who tested negative were coded as 0 . The input HTS data were stored in ESRI shapefile format and projected to the UTM coordinate system (WGS 84/UTM zone 32N) which covers the study area.

\section{RESULTS}

From the 3019 HTS spatial locations mapped, 720 (23.9\%) were positive cases while 2299 (76.1\%) tested negative, $328(45.6 \%)$ of the 720 positive cases identified in the community were thus estimated as being associated with the pre-targeted hotspots. The remaining $392(54.4 \%)$ were positive cases identified outside of the ROI of the originally targeted hotspots (Figure 1). The total number of mapped HTS points (both negative and positive cases) within the hotspot ROI was 1319, while those outside of the hotspot ROI were 1700 . The output of the Getis-Ord Gi* statistics conducted on 1700 HTS records - comprising positive and negative cases tested outside of the 75-m ROI of the originally targeted and mapped hotspots - presented seven categories of clusters and combinations of z-score and p-values defining each cluster type (Tables 1 and 2). The charts in (Figure 2A-C) also show the distribution across LGAs where the CAM activities are being implemented.

Of the total HTS points analyzed, $11 \%$ pointed to locations that were possible hotspots (HIV tests yielded $90-100 \%$ seropositive results), $15 \%$ pointed to the coldspots (mostly negative results), and $74 \%$ suggested areas of non-significant yields (mixed positives and negatives). The hotspots with the $99 \%$ confidence matched areas where the yield or positivity (a measure of positive cases surrounding an identified positive case within the distance band) was highest, hotspots within the 


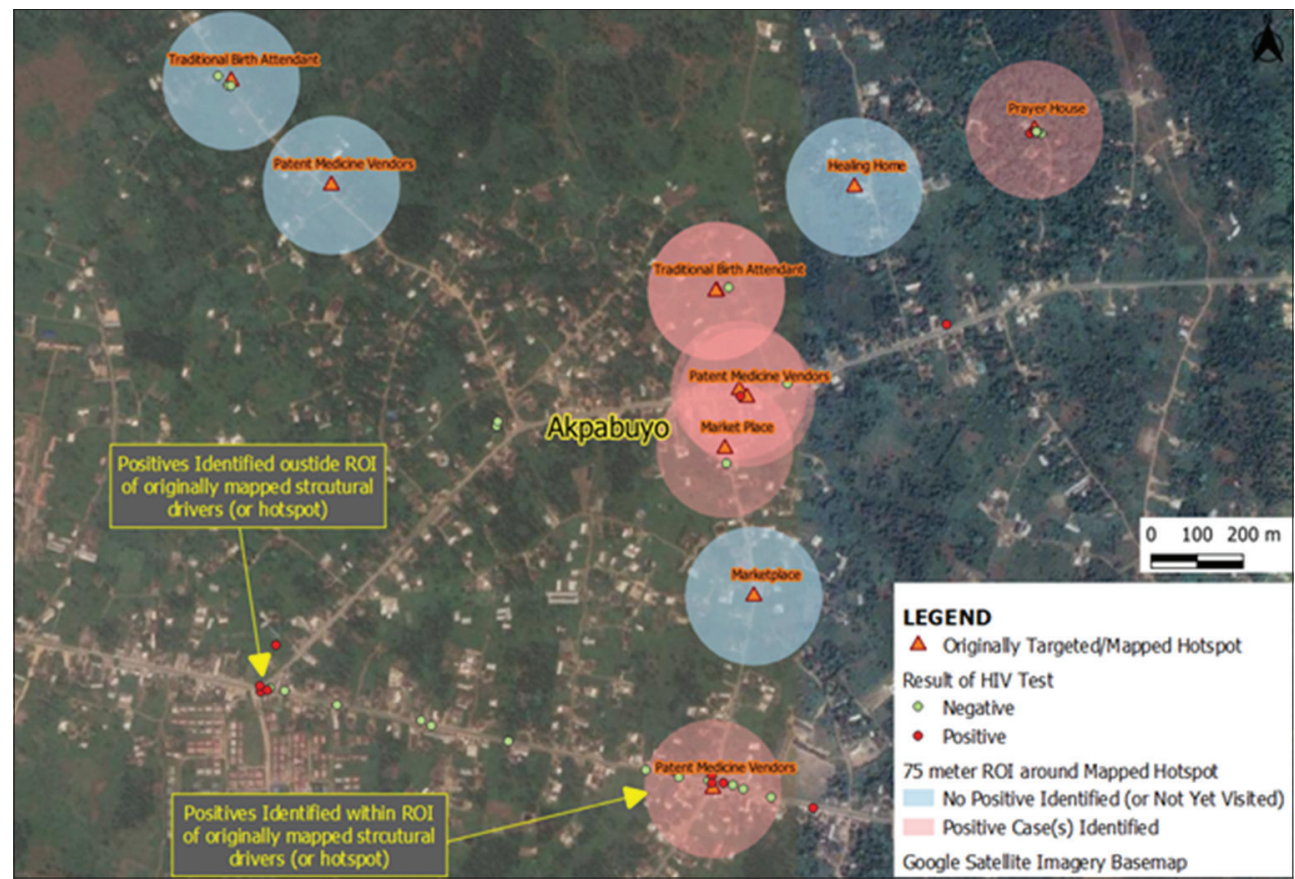

FIGURE 1. Sectional map of Akpabuyo LGA, Cross River State showing originally targeted "Hotspots."

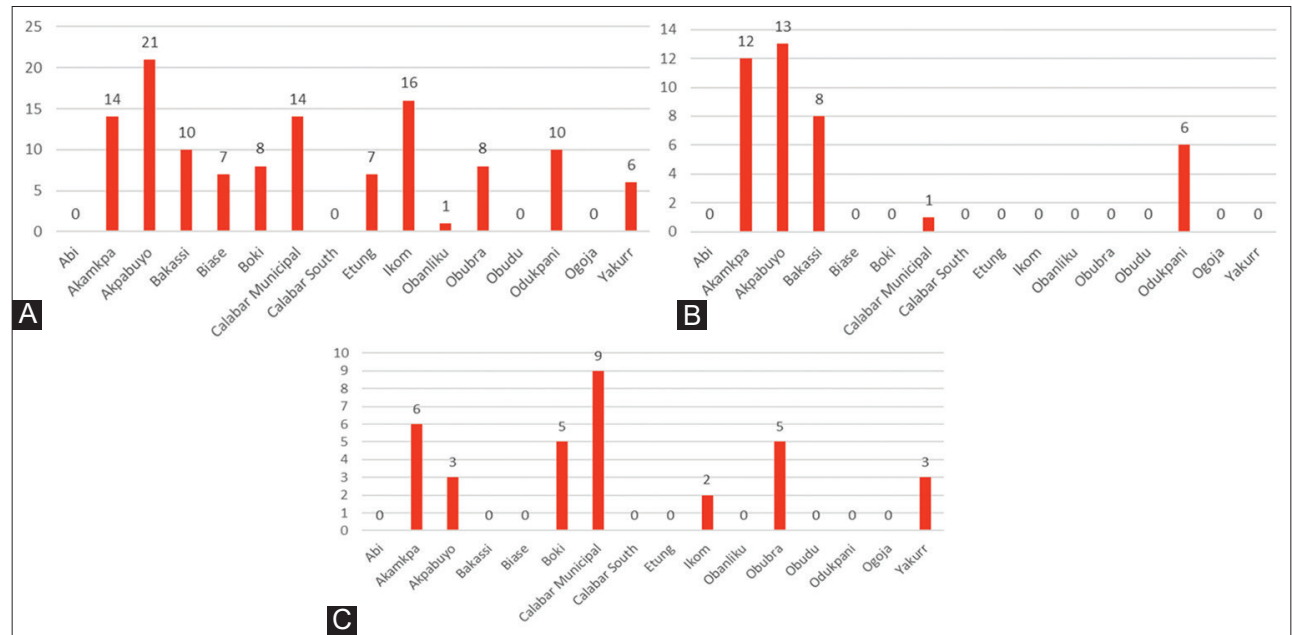

FIGURE 2. (A) Hotspots at $90 \% \mathrm{Cl}$ showing the distribution of HIV positive clients. (B) Hotspots at $95 \% \mathrm{Cl}$ showing the distribution of $\mathrm{HIV}$ positive clients. (C) Hotspots at $99 \% \mathrm{Cl}$ showing the distribution of HIV positive clients.

95\% confidence matched areas where positivity was moderate, and hotspots within the $90 \%$ confidence matched areas where positivity was relatively lower. The coldspots and non-significant clusters generally correspond to areas where positivity was very low (on average, $<30 \%$ ) based on associated positivity/ outcome of testing within the $500-\mathrm{m}$ band used for this analysis.

If a positive case (coordinate) is surrounded by most of the other positive cases within a proximity of $500 \mathrm{~m}$, that point is more likely to be classified as a hotspot; see Akamkpa, Akpabuyo, and 
TABLE 1. Distribution of HTS points in within respective cluster types by local government areas

\begin{tabular}{lcccccccc}
\hline LGA & $\begin{array}{c}\text { Coldspot }-90 \% \\
\text { confidence }\end{array}$ & $\begin{array}{c}\text { Coldspot } \\
-95 \% \\
\text { confidence }\end{array}$ & $\begin{array}{c}\text { Coldspot } \\
-99 \% \\
\text { confidence }\end{array}$ & $\begin{array}{c}\text { Not } \\
\text { significant }\end{array}$ & $\begin{array}{c}\text { Hotspot } \\
-90 \% \\
\text { confidence }\end{array}$ & $\begin{array}{c}\text { Hotspot } \\
-95 \% \\
\text { confidence }\end{array}$ & $\begin{array}{c}\text { Hotspot } \\
-99 \% \\
\text { confidence }\end{array}$ & Total \\
\hline Abi & 0 & 0 & 0 & 5 & 0 & 0 & 0 & 5 \\
Akamkpa & 0 & 0 & 0 & 157 & 14 & 12 & 6 & 189 \\
Akpabuyo & 0 & 0 & 0 & 129 & 21 & 13 & 3 & 166 \\
Bakassi & 0 & 0 & 0 & 61 & 10 & 8 & 0 & 79 \\
Biase & 0 & 0 & 0 & 17 & 7 & 0 & 0 & 24 \\
Boki & 0 & 0 & 0 & 37 & 8 & 0 & 5 & 50 \\
Calabar mun. & 44 & 115 & 6 & 309 & 14 & 1 & 9 & 498 \\
Calabar south & 18 & 15 & 0 & 118 & 0 & 0 & 0 & 151 \\
Etung & 0 & 0 & 0 & 13 & 7 & 0 & 0 & 20 \\
Ikom & 0 & 0 & 0 & 68 & 16 & 0 & 2 & 86 \\
Obanliku* & 0 & 0 & 0 & 1 & 1 & 0 & 0 & 2 \\
Obubra & 0 & 0 & 0 & 28 & 8 & 0 & 5 & 41 \\
Obudu & 0 & 0 & 0 & 2 & 0 & 0 & 0 & 2 \\
Odukpani & 34 & 17 & 0 & 232 & 10 & 6 & 0 & 299 \\
Ogoja* & 0 & 0 & 0 & 9 & 0 & 0 & 0 & 9 \\
Yakurr & 0 & 0 & 0 & 70 & 6 & 0 & 3 & 79 \\
Grand total & 96 & 147 & 6 & 1256 & 122 & 40 & 33 & 1700
\end{tabular}

${ }^{*}$ Ogoja and Obanliku LGAs were not covered by the CAM activities and so HTS points are cross-boundary spillovers

TABLE 2. Combination of z-score and $p$-values defining cluster types based on the Getis-Ord $\mathrm{Gi}^{*}$ statistics analysis

\begin{tabular}{|c|c|}
\hline Cluster type & Range of values defining clusters \\
\hline $\begin{array}{l}\text { Hotspot - 99\% } \\
\text { confidence }\end{array}$ & "z-score" $\geq 2.58$ and "p-value" $\leq 0.01$ \\
\hline $\begin{array}{l}\text { Hotspot }-95 \% \\
\text { confidence }\end{array}$ & $\begin{array}{l}\text { "z-score" } \geq 1.96 \text { and "z-score" }<2.58 \text { and } \\
\text { " } p \text {-value" } \leq 0.05 \text { and " } p \text {-value" }>0.01\end{array}$ \\
\hline $\begin{array}{l}\text { Hotspot - } 90 \% \\
\text { confidence }\end{array}$ & $\begin{array}{l}\text { "z-score" } \geq 1.65 \text { and "z-score" }<1.96 \text { and } \\
\text { "p-value" } \leq 0.1 \text { and " } p \text {-value" }>0.05\end{array}$ \\
\hline Not Significant & $\begin{array}{l}\text { "z-score" >-1.646 and "z-score" }<1.65 \\
\text { and "p-value" >0.1 }\end{array}$ \\
\hline $\begin{array}{l}\text { Coldspot - } 90 \% \\
\text { confidence }\end{array}$ & $\begin{array}{l}\text { "z-score" } \leq-1.646 \text { and "z-score" }>-1.96 \\
\text { and " } p \text {-value" } \leq 0.1 \text { and " } p \text {-value" }>0.05\end{array}$ \\
\hline $\begin{array}{l}\text { Coldspot - 95\% } \\
\text { confidence }\end{array}$ & $\begin{array}{l}\text { "z-score" } \leq-1.96 \text { and "z-score" }>-2.58 \\
\text { and " } p \text {-value" } \leq 0.05 \text { and " } p \text {-value" >0.01 }\end{array}$ \\
\hline $\begin{array}{l}\text { Coldspot - } 90 \% \\
\text { confidence }\end{array}$ & "z-score" $\leq-2.58$ and "p-value" $\leq 0.01$ \\
\hline
\end{tabular}

Bakassi in (Figure 2A-C). On the contrary, if a positive case is surrounded by mostly negative cases within the same distance band, it is likely classed under a coldspot (Figure 3). A fixed distance band of $500 \mathrm{~m}$ was used to cluster HIV positive cases within $500 \mathrm{~m}$ of a neighboring positive case. The $500-\mathrm{m}$ band was chosen in consideration of the relatively small sample size used of this analysis to at least guarantee a significant number of neighbors within major clusters. The output layer which had the $\mathrm{z}$-value and $p$-values generated for each of the HTS records allowed for the identification of spatial hotspots/coldspots as well as clusters/outliers in the input vector dataset. Positive and statistically significant z-scores indicated an intense cluster of high values (hotspot) and negative and statistically significant $\mathrm{z}$-scores indicated an intense cluster of low values (coldspot) (2,15). The mapped positive cases existing within a distance of $500 \mathrm{~m}$ from each other were re-clustered to provide a more visual representation of the areas of interest on the map. Each of the clusters was isolated from the others, where the positive cases existed at a distance greater than $500 \mathrm{~m}$.

\section{DISCUSSION}

The newly identified hotspots at 99\% confidence interval seem to correspond to more rural, hard-to-reach communities at the borders with a country (Cameroon), and/or state (AkwaIbom) with high HIV prevalence, 3.4\% and 5\%, 


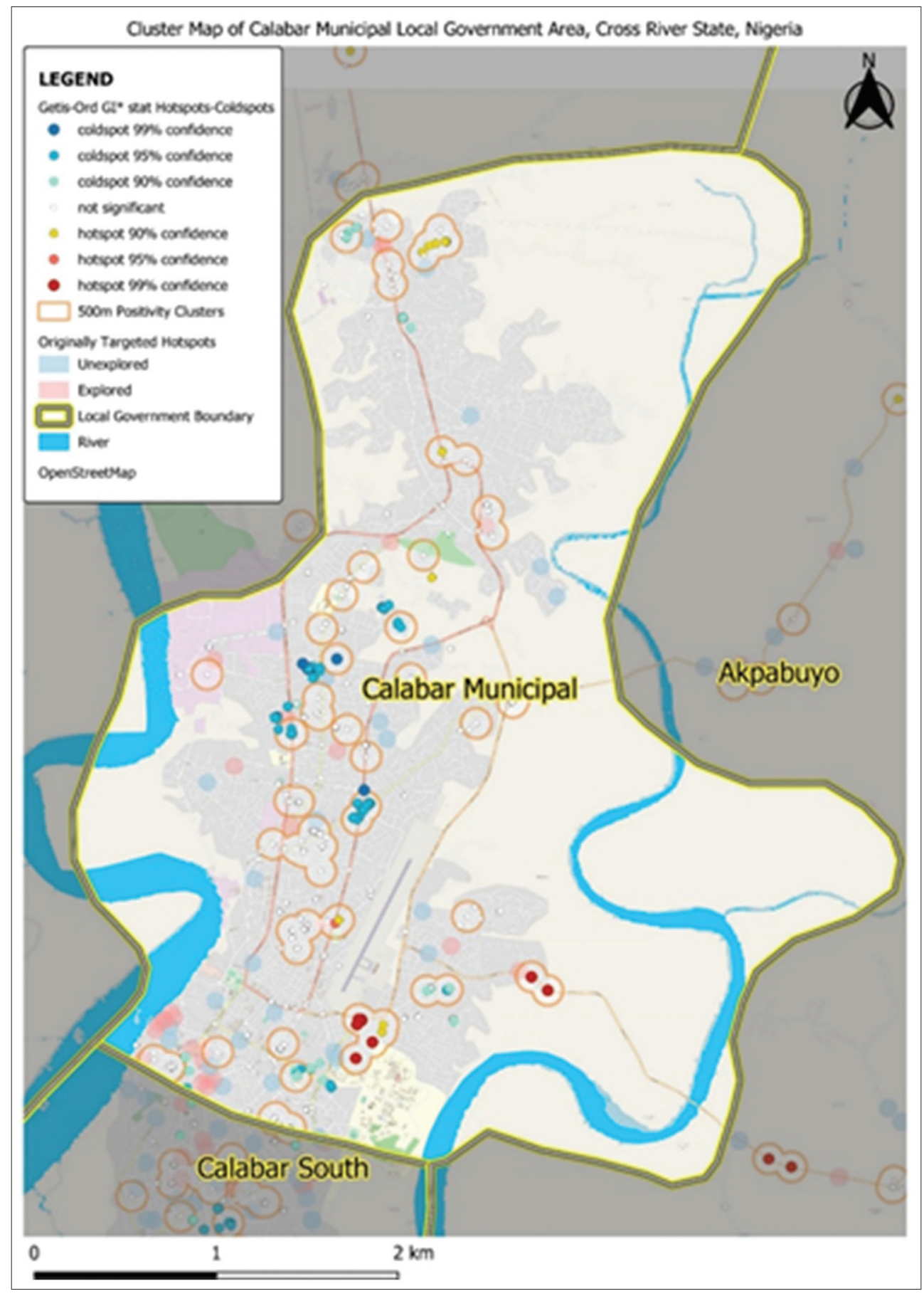

FIGURE 3. Sample cluster map of Calabar municipal LGA, Cross River State, Nigeria.

respectively $(6,7,16-18)$. Calabar municipality is the urban location closest to the three hotspots of
Akamkpa, Odukpani, and Bakassi LGAs. While Ikom serves as the closest urban area to Obubra, 
these border towns serve as transit cross-border high-risk clusters. The outputs from the GI* statistics served to validate the clusters by defining what sections of the clusters signified an inferred hotspot or coldspot.

While health facilities and/or prayer homes and TBAs (4) maintained the lead as hotspots within the $99 \%$ and $95 \% \mathrm{CI}$, their areas of influence outside a $500-\mathrm{m}$ radius showed areas where maritime and cross-boundary business occur seem to fit the model of locations where high-risk behaviors take place. These behaviors include but may not be limited to transactional sex and keeping multiple sexual partners by a highly mobile and seasonal cross-border migratory population. Research has shown that non-brothel-based sex workers are at higher risk of sexual abuse which in turn places them at higher risk of HIV infection (19). Unlike previously defined hotspots (TBAs, healing homes, PMVs) which seem to attract sick people, the new hotspots seem to be places where social gatherings and commercial interactions occur. The HIV-positive clusters around these locations may likely fuel an increased incidence of HIV, negating the drive for epidemic control as promoted by UNAIDS and NACA $(6,7,17)$.

\section{CONCLUSION}

The hotspots corresponded with more outskirts of urban centers and more rural, riverine communities with a large transient population of cross-border traders, fishermen, maritime workers, and inter-community taxi drivers. Transactional sex within and between a highly mobile population with a seasonal rural-urban migratory pattern may be fueling HIV infection and transmission in the area. Collectively, the clustering of the HTS points into the various groups provides some guidance as to what areas of the community to focus on and/ or prioritize targeted case identification. Areas currently determined as coldspots may likely change over time as community conflicts, weather changes, and sea/river levels are common determinants of shifts in migratory and residential patterns in these parts of the state. The GIS could help the CAM teams during their weekly planning meetings. They may focus on the areas with 99\% CI first, and subsequently, those with $95 \%$ and $90 \%$ CI. Therefore, their targeted testing may strategically avoid coldspots, saving costs while obtaining a high yield of positives.

\section{ACKNOWLEDGMENTS}

The research team wishes to thank the Cross River State Ministry of Health, the CAM teams, volunteers, and key gatekeepers within the communities of Central and South Senatorial Districts of Cross River State for identifying presumed hotspots that were later used as strategic points of reference in the GIS mapping.

\section{REFERENCES}

1. World Health Organization. Guidelines for Second Generation HIV Surveillance: An Update. Geneva, Switzerland: World Health Organization; 2013.

2. Prach LM, Treleaven E, Isiguzo C, Liu J. Care-seeking at patent and proprietary medicine vendors in Nigeria. BMC Health Serv Res 2015;15:231. https://doi.org/10.1186/s12913-015-0895-z.

3. Diamant J. The Countries with the 10 Largest Christian Populations and the 10 Largest Populations. Washington, DC: Pew Research Center; 2019. Available from: http://www.pewresearch.org. [Last accessed on 2020 Jul 04].

4. Ekpe ME, Ndep AO, Obegu PO, Ekpenyong BE, Moses E. Knowledge of and Preventive Practices to HIV Exposure among Traditional Birth Attendants in Calabar Metropolis, Cross River State, Nigeria. Atlanta, GA: American Public Health Association Annual Meeting and Expo; 2017.

5. Sarmento DR. Traditional Birth Attendance (TBA) in a health system: What are the roles, benefits and challenges: A case study of incorporated TBA in Timor-Leste. Asia Pac Fam Med 2014;13(1):12.

https://doi.org/10.1186/s12930-014-0012-1.

6. UNAIDS. HIV and AIDS in Nigeria. Geneva, Switzerland: Joint United Nations Programme on HIVIAIDS; 2019.

7. UNAIDS. Miles to Go: Closing Gaps, Breaking Barriers, Righting Injustices. Geneva, Switzerland: Joint United Nations Programme on AIDS; 2018.

8. Tsai PJ, Lin ML, Chu CM, Perng CH. Spatial autocorrelation analysis of health care hotspots in Taiwan in 2006. BMC Public Health 2009;9(1):464. https://doi.org/10.1186/1471-2458-9-464.

9. Getis A, Ord K. The analysis of spatial association by use of distance statistics. Geogr Anal 1992;24:189-206.

https://doi.org/10.1111/j.1538-4632.1992.tb00261.x.

10. Oxoli D, Prestifilippo G, Bertocchi D, Zurbaràn M. Enabling spatial autocorrelation mapping in QGIS: The hotspot analysis plugin. Geoingegneria Ambientale Mineraria 2017;151(2):45-50.

https://doi.org/10.7287/peerj.preprints.2204.

11. Ord K, Getis A. Local spatial autocorrelation statistics: Distributional issues and an application. Geogr Anal 2010;27:286-306.

https://doi.org/10.1111/j.1538-4632.1995.tb00912.x.

12. Anselin L. Local indicators of spatial association ISA. Geogr Anal 2010;27(2):93-115.

https://doi.org/10.1111/j.1538-4632.1995.tb00338.x.

13. Anselin L, Syabri I, Smirnov O, editors. Visualizing Multivariate Spatial Correlation with Dynamically Linked Window: New Tools for Spatial 
Analysis. Santa Barbara, CA: Specialist Meeting; 2002.

14. Wartenberg D. Multivariate spatial correlation: A method for exploratory geographical analysis. Geogr Anal 2010;17:263-83.

https://doi.org/10.1111/j.1538-4632.1985.tb00849.x.

15. Oxoli D. Hotspot Analysis Plugin for QGIS; 2018. Available from: https:// www.github.com/danioxoli/HotSpotAnalysis_Plugin. [Last accessed on 2020 Mar 14].

16. UNAIDS. Country Overview: Cameroon; 2020. Available from: http://www. unaids.org. [Last accessed on $2020 \mathrm{Apr} 25]$.

17. NACA. The 2018 National HIV/AIDS Indicator and Impact Survey (NAIIS)
National Summary Sheet: Preliminary Findings. Abuja, Nigeria: National Agency for the Control of AIDS; 2019.

18. Cameroon. Official Statistics of HIVIAIDS Prevalence Rate among Adults: Journal du Cameroun; 2020. Available from: http://www.journalducameroun.com. [Last accessed on 2020 Jun 03].

19. Wong ML, Teo AK, Tai BC, Ng AM, Lim RB, Tham DK, et al. Trends in unprotected intercourse among heterosexual men before and after brothe ban in Siem Reap, Cambodia: A serial cross-sectional study (2003-2012). BMC Public Health 2018;18(1):411.

https://doi.org/10.1186/s12889-018-5321-0. 